\title{
Análise de dados espaciais em saúde pública: métodos, problemas, perspectivas
}

\author{
Analysis of spatial data in public health: \\ methods, problems, and perspectives
}

\author{
1 Escola Nacional de Saúde \\ Pública, Fundação Oswaldo \\ Cruz, Rio de Janeiro, Brasil. \\ Correspondência \\ M. S. Carvalho \\ Departamento de \\ Epidemiologia e Métodos \\ Quantitativos em Saúde, \\ Escola Nacional \\ de Saúde Pública, \\ Fundação Oswaldo Cruz. \\ Rua Leopoldo Bulhões 1480, \\ Rio de Janeiro, $R J$ \\ 21041-210, Brasil. \\ carvalho@fiocruz.br
}

\begin{abstract}
Studies in which spatial distribution and geographic information systems (GIS) play a central role are becoming more common in the public health literature. However, methods and software to implement such approaches still pose serious limitations, due to unfriendliness and lack of integration. Additionally, most researchers and public health professionals are not familiar with either the techniques or the software. The aim of this work, besides presenting a systematic review of spatial analysis in health, is to discuss some representative applications of methods that deal with the analysis of spatial patterns of health events, analyzing advantages, disadvantages, and applicability of the proposed models in ecological and health services utilization studies.
\end{abstract}

Spatial Analysis; Geographic Information Systems; Review Literature
Marilia Sá Carvalho ${ }^{1}$

Reinaldo Souza-Santos 1

\section{Introdução}

Desde finais da década de 80 que na área da saúde vem se discutindo, e experimentando, diversas abordagens onde a localização espacial e os Sistemas de Informações Geográficas (SIG) têm papel destacado. Ainda que nos momentos iniciais estes estudos estivessem na contramão dos modelos analíticos vigentes na epidemiologia, baseado em abordagens estritamente individuais na busca por fatores de risco para doenças crônicas, em poucos anos operou-se um importante resgate do papel do ambiente sociocultural na determinação das doenças e, relacionado a isso, no acesso aos recursos e equipamentos de saúde: "o epidemiologista, ao gerar dados, não tem outra opção que ser um agente com influência social. A única questão é que tipo de influência" 1 (p. 1276).

Os denominados estudos ecológicos, definidos como estudos onde se focaliza a comparação de grupos, ao invés de indivíduos, teriam como razão subjacente o fato de que dados em nível individual da distribuição conjunta de duas (ou talvez todas) variáveis não estariam disponíveis internamente nos grupos. Assim, o estudo ecológico seria um desenho incompleto 2 . Esta ainda é uma visão dominante, particularmente no contexto mais acadêmico. Nos países periféricos, entretanto, a pesquisa em epidemiologia sempre teve forte associação com a prática dos serviços de saúde pública, 
possivelmente por ter nestes parceiros, financiadores importantes, cumprindo um papel essencial no que se definiu como "informação para ação".

O papel dos tipos clássicos de investigação - os diagnósticos de saúde - em epidemiologia está na ênfase que se dá às doenças da população em oposição às doenças do indivíduo. A pergunta que se deseja responder neste caso, não é sobre as causas dos casos de doença, mas sobre as causas da incidência da doença em grupos populacionais, comparando diferentes populações, em geral definidas como moradores de uma mesma área. $\mathrm{O}$ interesse focaliza-se não na doença em populações, mas na doença de populações, o objetivo é ver a "floresta e não as árvores". A visão centralizada no indivíduo leva ao uso do risco-relativo como a representação básica da força etiológica: ou seja, o risco em indivíduos expostos relativo aos não-expostos. Embora esta seja a melhor medida de força etiológica, não é a de maior importância em saúde pública 3 .

A fim de compreender como um contexto afeta a saúde de grupos populacionais por meio de seleção, distribuição, interação, adaptação e outras respostas, torna-se necessário medir efeitos em nível de grupo, uma vez que medidas em nível individual não podem dar conta destes processos 4 . Recentes avanços metodológicos no campo da estatística, particularmente os denominados modelos de efeitos aleatórios, trazem perspectivas inovadoras para a análise, superando o fato de que "grande parte da pesquisa atual em epidemiologia está baseada no individualismo metodológico: a noção que a distribuição da saúde e doença em populações pode ser explicada exclusivamente em termos das características dos indivíduos" 5 (p. 216). Neste mesmo campo, investigações de efeitos denominados de vizinhança apontam para os "riscos associados com a estrutura social e ecológica de vizinhança, enseja-se possíveis intervenções inovadoras no nível da comunidade" 6 (p. 111). Padrões de mortalidade ou morbidade, propagação de epidemias, transmissão sexual de doenças ou a transferência de comportamentos ou valores não podem ser explicados sem uma abordagem que além de considerar os grupos estude o espaço e o tempo.

Por outro lado, na área relacionada à prestação de serviços em saúde diversas aplicações permitem estudar aspectos geográficos no uso dos serviços de saúde, trazendo novas informações para a discussão da eqüidade, ao analisar o acesso geográfico, as diferenças no uso segundo aspectos sócio-econômicos. Além disso, novos ramos se desenvolvem, ganhando im- portância cada vez maior os estudos ambientais. Em resumo, os métodos de análise espacial na saúde coletiva vêm sendo usados principalmente em estudos ecológicos, na detecção de aglomerados espaciais ou espaço-temporais, na avaliação e monitoramento ambiental e aplicados ao planejamento e avaliação de uso de serviços de saúde 7,8 .

Recente revisão sobre o uso de SIGs e ferramentas de análise espacial em saúde pública aponta para o desenvolvimento de ferramentas que integrem funções de processamento e análise de informações georreferenciadas, cuja implantação dependerá entretanto, da demanda de métodos de análise espacial, pela comunidade da área da saúde pública 9 . Entretanto, embora bastante extenso, e talvez por causa disso, a modelagem estatística espacial e a integração entre SIG e estatística não são aprofundadas. Alguns livros excelentes publicados nos últimos anos procuram fazer a ponte entre métodos estatísticos espaciais e aplicações em saúde pública 10,11,12, e praticamente ignoram os aspectos ligados ao gerenciamento da informação geocodificada em SIGs. Por outro lado, livros voltados para os SIGs pouco desenvolvem as questões estatísticas e de modelagem dos processos 13 .

Um aspecto deve ser considerado: esta é uma área de investigação onde a inter (ou trans) disciplinariedade mais do que desejável é imprescindível. Além de conhecer profundamente o problema em questão, os métodos necessários à incorporação nos estudos da dimensão espacial, ou espaço-temporal, envolvem, no mínimo, conhecimentos de SIGs e técnicas estatísticas bastante sofisticadas. Isso porque a existência de padrões espaciais implica a incorporação aos modelos estatísticos de estruturas de correlação entre as observações. Os modelos mais complexos freqüentemente só podem ser estimados usando-se inferência bayesiana, ainda pouco empregada no contexto da epidemiologia e da saúde pública em geral.

Mesmo considerando que o custo da aquisição da informação ainda seja elevado (vem caindo dramaticamente nos últimos anos); que o treinamento formal na área ainda seja escasso (apesar da oferta de diversos cursos de atualização); e que os programas de computador não sejam muito amistosos, acreditamos que o reconhecimento do potencial desses métodos na área da saúde coletiva permitirá ampliar seu uso e estimular a criação de redes cooperativas interdisciplinares. O objetivo deste trabalho é apresentar algumas aplicações exemplares de métodos voltados para a análise de padrões espaciais de eventos em saúde, discutindo vanta- 
gens, desvantagens e aplicabilidade dos modelos propostos, particularmente no campo dos estudos ecológicos e na análise do uso de serviços de saúde, além de sistematizar o estado da arte da utilização de metodologias de análise espacial em estudos ecológicos na área da saúde pública. Esperamos contribuir para que pesquisadores especialistas em cada um dos campos relacionados - epidemiologia, geografia, planejamento em saúde, estatística, sistemas de informações - aproveitem esta reflexão no uso e na produção de ferramentas que viabilizem este tipo de estudo.

\section{Análise espacial: aplicações em saúde}

Na busca de referências bibliográficas nas bases MEDLINE e SciELO, utilizando-se o termo "spatial analysis" em combinação com "public health", "epidemiology", "health service” e “access”, para o período de 1999 a 2004, foram identificadas 58 referências. Foram incluídos artigos em inglês, português, espanhol ou francês e excluídos os artigos de revisão.

A primeira constatação é que alguma técnica estatística estava presente em 49 trabalhos $(84,5 \%)$, das quais apenas $5(10,0 \%)$ não apropriadas a dados espaciais. Entre os artigos cuja origem não é brasileira, métodos de regressão incorporando a estrutura espacial e métodos de detecção de cluster foram os mais empregados (5 e 4, respectivamente). SIGs estavam referidos em 11 do total de artigos, e modelos estatísticos complexos, utilizando inferência bayesiana, em apenas 5. Nenhum artigo utilizava estas duas ferramentas em conjunto.

O quadro brasileiro é semelhante: 6 estudos utilizaram metodologia bayesiana, 4 detecção de cluster, 2 regressão e 7 SIG. Apenas 1 utilizou detecção de cluster com a organização das bases de dados em ambiente de SIG. Exceção é o projeto SAUDAVEL, coordenado pelo Instituto Nacional de Pesquisas Espaciais (INPE), que tem como objetivo "encontrar as respostas $e$ produzir os instrumentos de Tecnologia de Informação Espacial, métodos, algoritmos $e$ produtos de software, para dotar os sistemas de vigilância epidemiológica, e de controle de endemias, de capacidade de antecipação, a partir da possibilidade de tratar grandes bases de dados espaço-temporais, com dados dos Sistema de Informação em Saúde [...]” 14.

A estratificação dos temas por artigos nos mostra que 29 (50,0\%) são sobre doenças transmissíveis, 8 causas externas, 8 doenças crônicas, 6 saúde materno-infantil, 5 sobre acesso e 6 sobre outros temas. Vale ressaltar que o Brasil contribuiu com 17 dos 29 artigos que versam sobre doenças transmissíveis e com nenhum sobre doenças crônicas (Tabela 1).

A evolução temporal das publicações evidencia a presença marcante de trabalhos brasileiros no cenário internacional. Dos 58 artigos selecionados no período de 1999 a 2004, 24 $(41,4 \%)$ e $13(22,4 \%)$ foram publicados em 2001 e 2002, sendo 18 e 4 desenvolvidos no Brasil, respectivamente. Do total de artigos, o Brasil contribuiu com 28 (48,3\%), seguido pelos Estados Unidos e Canadá com 14 (24,1\%) e Europa com 6 (10,3\%) artigos (Tabela 2). É importante salientar que o maior número de artigos brasileiros publicados em 2001 é decorrente de um fascículo temático publicado na revista Cadernos de Saúde Pública, em 2001, denominado Análise de Dados Espaciais em Saúde.

Independente da publicação deste fascículo temático, os números aqui apresentados mostram a presença marcante de pesquisadores brasileiros ao longo dos anos. Apesar deste cenário, existem muitas dúvidas, por parte de pesquisadores e de profissionais dos serviços de saúde, quanto a vantagens, desvantagens e aplicabilidade de alguns modelos, que serão discutidos a seguir.

\section{Estudos ecológicos}

Os principais objetivos dos estudos ecológicos são a identificação de regiões de sobre-risco em relação à média global do processo estudado e a busca de fatores potencialmente explicativos dos diferenciais de incidência encontrados, seja no campo da análise exploratória, “mapeando" doenças, ou buscando modelos explicativos, identificando diferenciais de risco e apontando medidas preventivas. Duas questões essenciais neste tipo de modelagem norteiam toda a discussão que se segue: a estrutura de dependência entre amostras e a flutuação aleatória dos indicadores ecológicos.

Ao se estabelecer um modelo de regressão buscando relacionar uma variável resposta a variáveis independentes, um dos pressupostos básicos da estatística, da independência entre amostras, é pouco realístico: na verdade, nos dados espaciais " a dependência está presente em todas as direções e fica mais fraca à medida em que aumenta a dispersão na localização dos dados" 15 (p. 3).

Por outro lado, os estudos ecológicos engendram uma contradição importante entre aumento na escala e estabilidade de indicadores: ao diminuir a área das unidades espaciais aumenta-se a homogeneidade interna dos gru- 
Artigos disponibilizados no MEDLINE e SciELO, entre 1999 e 2004, segundo tema e região de origem

\begin{tabular}{|c|c|c|c|c|c|c|c|}
\hline & $\begin{array}{l}\text { Acesso ao } \\
\text { serviço }\end{array}$ & $\begin{array}{c}\text { Causas } \\
\text { externas }\end{array}$ & $\begin{array}{l}\text { Doenças } \\
\text { crônicas }\end{array}$ & $\begin{array}{l}\text { Saúde materno- } \\
\text { infantil }\end{array}$ & $\begin{array}{c}\text { Doenças } \\
\text { transmissíveis }\end{array}$ & Outros & Total \\
\hline \multicolumn{8}{|c|}{ América do Norte } \\
\hline $\mathrm{n}$ & 133 & $534,35,36,37,38$ & $339,40,41$ & 142 & $443,44,45,46$ & 0 & 14 \\
\hline$\%$ & 7,1 & 35,7 & 21,4 & 7,1 & 28,6 & 0,0 & 100,0 \\
\hline \multicolumn{8}{|c|}{ América do Sul } \\
\hline $\mathrm{n}$ & 147 & 0 & 0 & 0 & 0 & 0 & 1 \\
\hline$\%$ & 100,0 & 0,0 & 0,0 & 0,0 & 0,0 & 0,0 & 100,0 \\
\hline \multicolumn{8}{|c|}{ África } \\
\hline $\mathrm{n}$ & 148 & 0 & 0 & 0 & $649,50,51,52,53,54$ & 0 & 7 \\
\hline$\%$ & 14,3 & 0,0 & 0,0 & 0,0 & 85,7 & 0,0 & 100,0 \\
\hline \multicolumn{8}{|l|}{ Ásia } \\
\hline $\mathrm{n}$ & 0 & 0 & 0 & 0 & 155 & 0 & 1 \\
\hline$\%$ & 0,0 & 0,0 & 0,0 & 0,0 & 100,0 & 0,0 & 100,0 \\
\hline \multicolumn{8}{|c|}{ Brasil } \\
\hline$n$ & 156 & $357,58,59$ & 0 & $524,60,61,62,63$ & $17^{*}$ & 280,81 & 28 \\
\hline$\%$ & 3,6 & 10,7 & 0,0 & 17,9 & 60,7 & 7,1 & 100,0 \\
\hline \multicolumn{8}{|c|}{ Europa } \\
\hline$n$ & 0 & 0 & $582,83,84,85,86$ & 0 & 187 & 0 & 6 \\
\hline$\%$ & 0,0 & 0,0 & 83,3 & 0,0 & 16,7 & 0,0 & 100,0 \\
\hline \multicolumn{8}{|c|}{ Oceania } \\
\hline$n$ & 188 & 0 & 0 & 0 & 0 & 0 & 1 \\
\hline$\%$ & 100,0 & 0,0 & 0,0 & 0,0 & 0,0 & 0,0 & 100,0 \\
\hline \multicolumn{8}{|c|}{ Total } \\
\hline $\mathrm{n}$ & 5 & 8 & 8 & 6 & 29 & 2 & 58 \\
\hline$\%$ & 8,6 & 13,8 & 13,8 & 10,3 & 50,0 & 3,4 & 100,0 \\
\hline
\end{tabular}

* $16,64,65,66,67,68,69,70,71,72,73,74,75,76,77,78,79$.

pos populacionais residentes. Assim, busca-se evitar o problema dos indicadores refletirem médias pouco esclarecedoras do processo onde subpopulações com grau diferenciado de risco coexistem em espaços geográficos muito próximos. Por outro lado, ao diminuir a área da unidade de análise diminui também sua população e conseqüentemente enfrenta-se a instabilidade típica de pequenos números. É muito comum que o município ou bairro com a maior taxa de mortalidade infantil seja um local onde nascem poucas crianças. O indicador estimado simplesmente dividindo óbitos infantis pelo número de nascidos vivos neste caso não é o melhor estimador.

A modelagem simultânea ou separadamente dos dois aspectos - busca de explicação e detecção de regiões de sobre-risco - foi desenvolvida em duas vertentes principais, conforme o tipo de dado disponível, se pontuais (individuais) ou agregados em áreas. Cabe ressal- tar que os modelos envolvem um grau de complexidade estatística que impõe o uso de programa de computador especializado, com todos os problemas decorrentes da interface (ou falta de) com os SIGs e, principalmente, com o usuário.

Apresentaremos estudos com abordagens metodológicas substancialmente diferentes. Os dois primeiros utilizam dados agregados por áreas, visando a suavizar a flutuação aleatória relacionada a pequenas populações e estimando os parâmetros de regressão ecológica. No terceiro exemplo se discute a utilização de métodos voltados para análise de processos pontuais, modelando simultaneamente variáveis individuais e a localização pontual dos indivíduos, identificando regiões de sobre-risco, bastante diferente portanto dos estudos ecológicos clássicos baseados em medidas agregadas. Optamos por denominá-lo ecológico propositadamente, para ampliar o conceito estreito da 
Artigos disponibilizados no MEDLINE e SciELO, segundo região de origem e ano de publicação.

\begin{tabular}{|c|c|c|c|c|c|c|c|}
\hline & 1999 & 2000 & 2001 & 2002 & 2003 & 2004 & Total \\
\hline \multicolumn{8}{|c|}{ América do Norte } \\
\hline $\mathrm{n}$ & 0 & 239,41 & $335,45,46$ & $438,40,42,44$ & $533,34,36,37,43$ & 0 & 14 \\
\hline$\%$ & 0 & 25,0 & 12,5 & 30,8 & 71,4 & 0,0 & 24,1 \\
\hline \multicolumn{8}{|c|}{ América do Sul } \\
\hline $\mathrm{n}$ & 147 & 0 & 0 & 0 & 0 & 0 & 1 \\
\hline$\%$ & 33,3 & 0,0 & 0,0 & 0,0 & 0,0 & 0,0 & 1,7 \\
\hline \multicolumn{8}{|c|}{ África } \\
\hline $\mathrm{n}$ & 0 & 152 & 251,54 & 250,53 & 0 & 248,49 & 7 \\
\hline$\%$ & 0,0 & 12,5 & 8,3 & 15,4 & 0,0 & 66,7 & 12,1 \\
\hline \multicolumn{8}{|l|}{ Ásia } \\
\hline $\mathrm{n}$ & 0 & 0 & 0 & 0 & 155 & 0 & 1 \\
\hline$\%$ & 0,0 & 0,0 & 0,0 & 0,0 & 14,3 & 0,0 & 1,7 \\
\hline \multicolumn{8}{|c|}{ Brasil } \\
\hline $\mathrm{n}$ & 0 & $458,71,76,79$ & $18^{*}$ & $474,77,78,80$ & 172 & 173 & 28 \\
\hline$\%$ & 0,0 & 50,0 & 75,0 & 30,8 & 14,3 & 33,3 & 48,3 \\
\hline \multicolumn{8}{|c|}{ Europa } \\
\hline $\mathrm{n}$ & 185 & 187 & 186 & $382,83,84$ & 0 & 0 & 6 \\
\hline$\%$ & 33,3 & 12,5 & 4,2 & 23,1 & 0,0 & 0,0 & 10,3 \\
\hline \multicolumn{8}{|c|}{ Oceania } \\
\hline $\mathrm{n}$ & 188 & 0 & 0 & 0 & 0 & 0 & 1 \\
\hline$\%$ & 33,3 & 0,0 & 0,0 & 0,0 & 0,0 & 0,0 & 1,7 \\
\hline \multicolumn{8}{|c|}{ Total } \\
\hline $\mathrm{n}$ & 3 & 8 & 24 & 13 & 7 & 3 & 58 \\
\hline$\%$ & 100,0 & 100,0 & 100,0 & 100,0 & 100,0 & 100,0 & 100,0 \\
\hline
\end{tabular}

* $16,24,56,57,59,60,61,62,63,64,65,66,67,68,69,70,75,81$

denominação ecológico na epidemiologia, resgatando o sentido mais amplo da palavra, como o estudo das complexas inter-relações entre organismos vivos e o seu meio físico.

\section{Áreas de maior risco e regressão ecológica}

A identificação de áreas onde é maior o risco é um dos pilares dos estudos ecológicos bem como da epidemiologia social. A primeira questão que deve ser tratada, entretanto, é a flutuação aleatória dos indicadores, conseqüência de eventos raros em pequenas populações. A forma mais simples consiste em utilizar as observações das áreas vizinhas - casos e população para ponderar as taxas das regiões com pequena população. A idéia é fazer a estimativa da taxa convergir em direção a uma média local ou global. Evidentemente a local é mais adequada, pois preserva a similaridade esperada entre vizinhos. Cada área terá suas taxas reestimadas aplicando-se uma média ponderada entre o valor medido e a taxa média local, sendo este peso inversamente proporcional à população da região 11 . Ao aplicarmos esta correção às taxas de regiões densamente povoadas, estas não serão alteradas.

A Figura 1 mostra o resultado do mapeamento das taxas brutas de detecção de hanseníase no período 1993-1997 16 e as taxas suavizadas utilizando método bayesiano empírico 17. O peso excessivo que as áreas maiores e menos densas recebiam na inspeção visual, bem como a grande ocorrência de áreas com taxa zero (identificadas com círculo) no mapa suavizado ficam muito bem resolvidos.

A implementação do método pode ser feita, atualmente, utilizando-se a biblioteca SPDEP 18 do programa de domínio público R 19. Este tem grande flexibilidade e permite o ajuste de diversos modelos utilizados na análise espacial, embora exija do usuário algum domínio da 

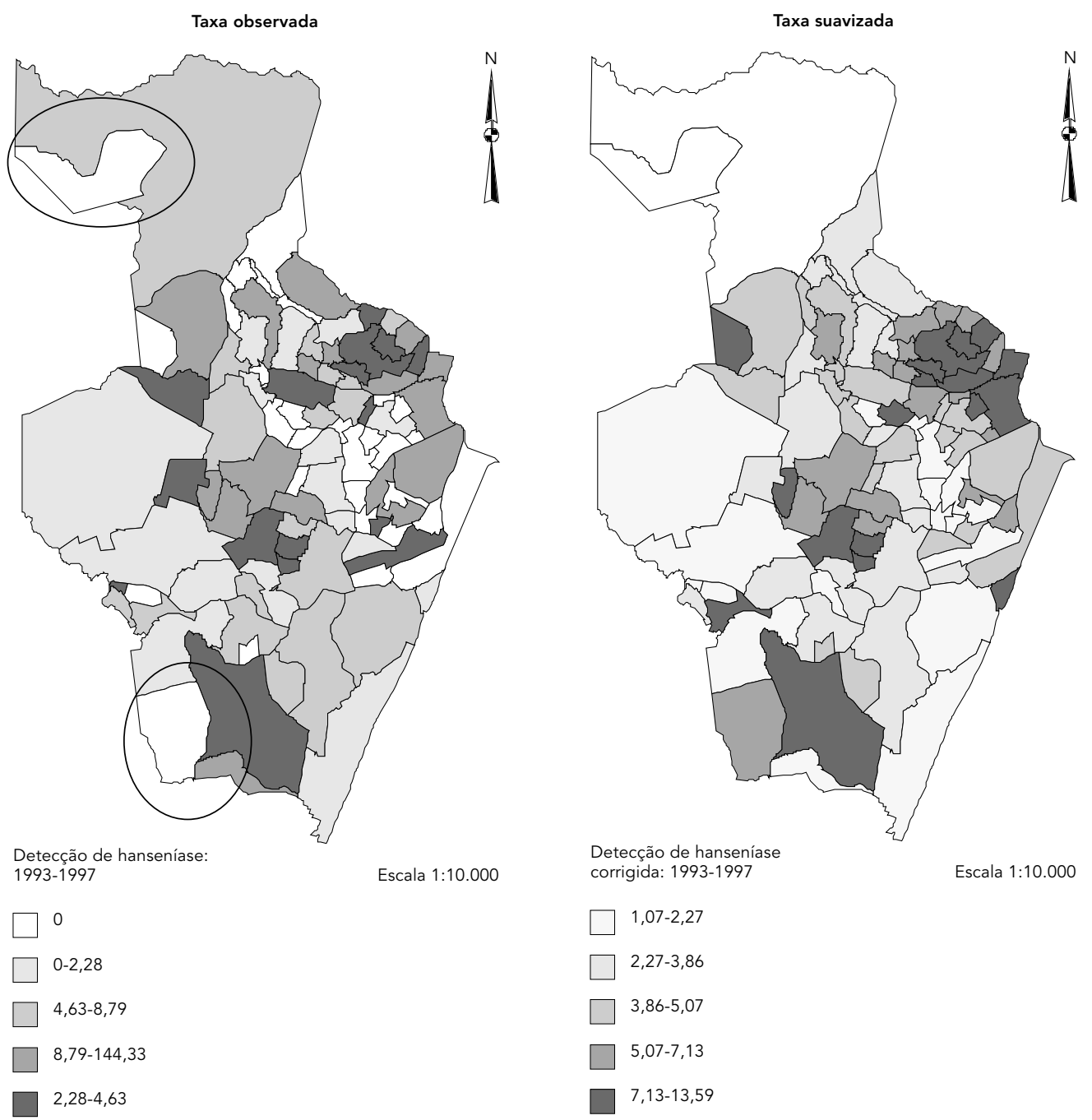

Fonte: Souza et al. 16.

linguagem, toda em linha de comando. A forma mais simples de importar os dados para este programa é em texto puro ou por meio da recentemente desenvolvida interface entre TabWin e R (http://www.datasus.gov.br/tabwin/ apresent.htm, acessado em 26/Dez/2004).

O maior problema na implementação é a construção da matriz de vizinhança, que seria facilmente solucionável em ambiente de SIG. Além disso, se considerarmos que a própria definição de vizinhança pode variar conforme o tipo de problema - fronteira comum, mesma rede de água, menor distância entre centros populacionais, entre outras - aumenta a necessidade de que este tipo de solução seja implementado em ambiente SIG.

\section{Regressão ecológica}

Os modelos mais usuais são os denominados CAR (Conditional Auto Regressive), onde se inclui na regressão linear um efeito aleatório condicionado pela vizinhança. O mesmo programa (R) e os mesmos problemas de criação da matriz de vizinhança estão presentes. Entretanto, neste ambiente só é possível estimar a 
regressão linear, onde a variável resposta possui distribuição normal. Considerando que os dados são contagens - casos ou óbitos da doença em estudo - seria mais interessante utilizar modelos lineares próprios para distribuição de Poisson. Além disso, dada a flutuação aleatória dessas contagens, o modelo mais adequado deve considerar simultaneamente a estimativa dos parâmetros da regressão e a estabilização dos indicadores, modelos estes usualmente ajustados utilizando ferramentas desenvolvidas no campo da inferência bayesiana.

O exemplo a seguir mostra um modelo desenvolvido para identificação de áreas de subregistro de hanseníase em Olinda, Pernambuco 20 . A idéia surgiu a partir da constatação de que, embora houvesse forte (e esperada) correlação entre taxas de detecção de hanseníase e todos os indicadores de carência social, esta correlação desaparecia nas áreas mais carentes. A hipótese, evidentemente, não era de que a miséria (mais de $60,0 \%$ dos chefes de família com renda mensal inferior a um salário mínimo) fosse fator de proteção para hanseníase, mas que nessas áreas até mesmo a detecção da doença estava prejudicada e, conseqüentemente, o acesso à assistência. Os objetivos do modelo neste estudo são: estimar a associação entre carência social e hanseníase, e quantificar quantos casos seriam esperados nas áreas onde se suspeita detecção deficiente, dirigindo assim as atividades dos serviços de controle de hanseníase. A forma de fazer isso utiliza a informação da vizinhança, estendendo a idéia por trás do alisamento bayesiano: considera-se que o número de casos de hanseníase nas áreas com mais de $60,0 \%$ de chefes de família com renda inferior a um salário mínimo deve ser superior ao detectado, e nem o estimador bruto (casos detectados por 10 mil habitantes) nem o estimador com alisamento espacial filtrando a flutuação aleatória expressam o processo da hanseníase em Olinda. Neste caso, o modelo estima além dos parâmetros da regressão o número esperado de casos em cada setor, dado o valor do indicador e o número de casos na vizinhança.

A Figura 2, baseada nos modelos do artigo citado 20 , porém refeita e adaptada neste trabalho visando ao maior didatismo, apresenta no primeiro quadro o indicador de carência social, e nos dois seguintes o risco relativo de detecção de hanseníase de cada setor censitário: risco bruto, alisamento bayesiano com correção de sub-registro (quadros B e C). No último quadro são destacados os setores onde o modelo indica grande número de casos não detectados. É interessante observar que com o início do funcionamento do Programa Saúde da Família, em Olinda, o número de casos detectados de hanseníase aumentou substancialmente, aproximadamente nas áreas indicadas pelo modelo.

Evidentemente este tipo de modelagem ainda está bastante distante da prática da epidemiologia. O uso de inferência bayesiana e de ferramentas de estimação como o MCMC (Markov Chain Monte-Carlo), atualmente muito comuns na literatura estatística ainda não é usual na saúde coletiva. Entretanto, a flexibilidade demonstrada neste exemplo traz muitos benefícios. É importante ressaltar que existe software gratuito - neste caso o WinBugs 21 - que permite a modelagem. Os passos necessários na implementação do modelo vão da entrada de dados no WinBugs, o processo de modelagem bayesiana até o retorno ao SIG para interpretação dos resultados. Do ponto de vista prático, a entrada de dados no WinBugs é a etapa que apresenta maior dificuldade. A informação de vizinhança entra no programa como uma lista, onde para cada setor se informa o número de vizinhos e seus códigos. É um processo demorado e com diversas possibilidades de erros. Como parte do processo de modelagem bayesiana, deve-se realizar análise de convergência, que é facilitada pela existência de uma função específica no $\mathrm{R}$, que importa diretamente a saída do WinBugs. Ao final, os parâmetros estimados devem ser exportados para o SIG, onde são feitos os mapas, novamente de forma não automatizada.

Esse tipo de modelo pode também trazer contribuições interessantes em demografia, onde freqüentemente as causas de sub-registros têm forte componente social. Outros aspectos como distância de centros de saúde ou outros serviços potencialmente relacionados ao assunto em estudo também poderiam ser incluídos no modelo, caso a ligação entre SIG e programa estatístico fosse mais simples.

\section{Indivíduos e regiões}

Neste tipo de modelo busca-se tratar simultaneamente aspectos do indivíduo e aspectos socioambientais, partindo da localização pontual da residência, e tratando o espaço como superfície contínua. É um desenho do tipo caso-controle (variável resposta binomial), onde as coordenadas geográficas dos eventos são analisadas em uma superfície contínua (sem divisões político-administrativas) construída por um kernel 22 como em um modelo aditivo generalizado 23. No exemplo a seguir os casos são os óbitos pós-neonatais e os controles uma amos- 
Figura 2

Indicador de carência social (a), risco relativo para hanseníase (b), risco corrigido (c), áreas prioritárias para busca ativa (d).

Olinda, Pernambuco, Brasil, 1991-1996.
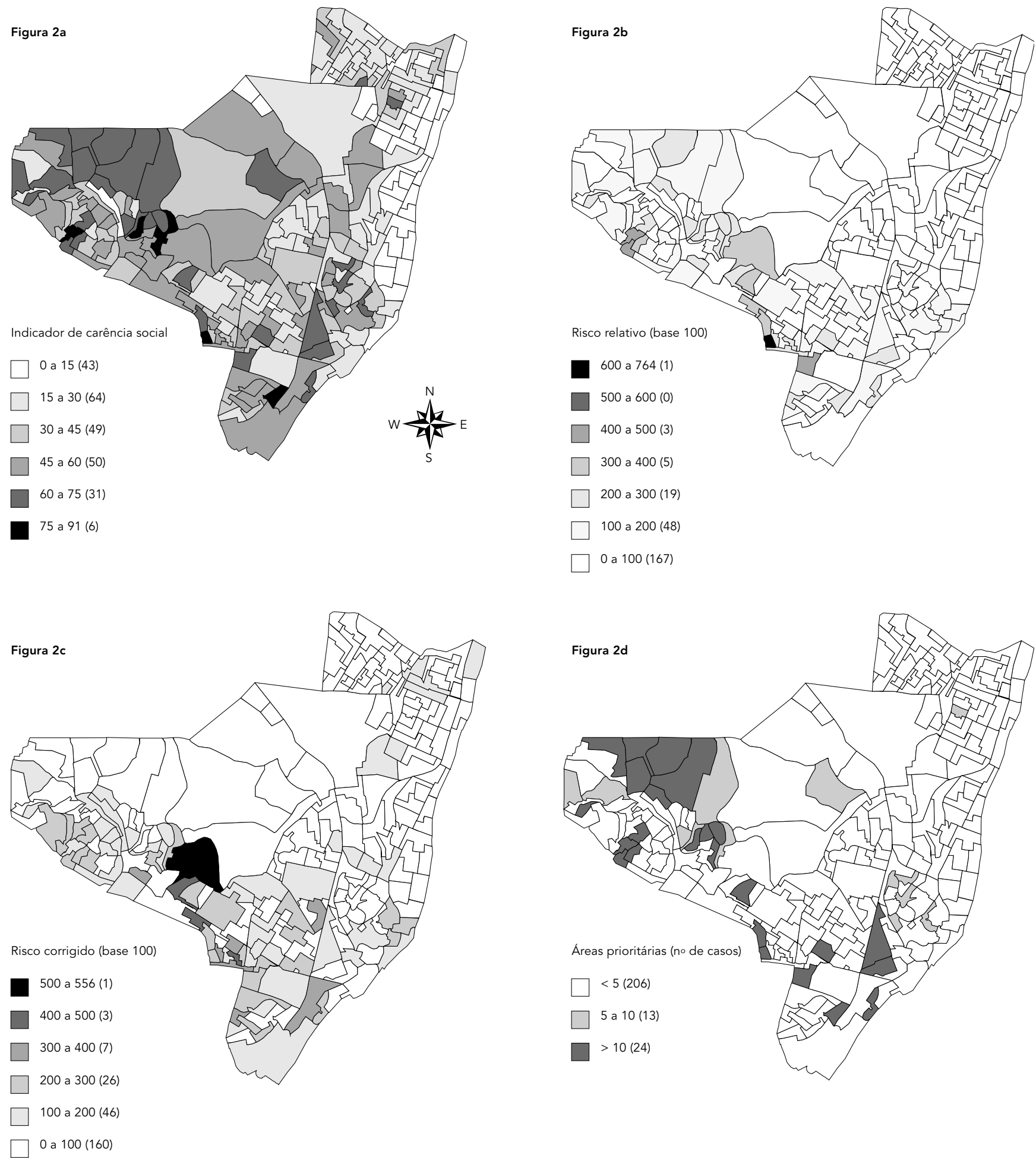

Modificado de Bailey et al. 20. 
tra de nascidos vivos retirada do SINASC (Sistema de Informações de Nascidos Vivos). Foram analisadas as seguintes covariáveis: sexo, peso ao nascer, idade da mãe, instrução da mãe, duração da gestação, tipo de gravidez (única ou gemelar) e tipo de parto (cesariana ou normal). Como nosso objetivo não é detalhar a técnica 24,25, mas discutir sua importância e aplicabilidade, passaremos direto aos resultados, resumidos na Figura 3 e na Tabela 3.

Na Figura 3 são apresentados: (3A) localização pontual da residência de amostra dos nascidos vivos registrados no SINASC; (3B) localização dos óbitos infantis (neo-natal e pós-neonatal) do ano de 1998; e (3C) a identificação de áreas com risco significativamente maior para a mortalidade pós-neonatal (de 28 dias a um ano). Na Tabela 3, entre os parâmetros estimados para cada covariável, o peso ao nascer destaca-se como importante fator de risco para o óbito e a instrução da mãe como fator de proteção.

A primeira grande vantagem na utilização desse tipo de modelo é que a localização pontual de óbitos e população a risco (amostra), quando disponíveis, evita o particionamento artificial da região, baseado em critérios político-administrativos que podem não ter relação com o objeto de estudo. A própria escolha da escala do estudo deixa de ser um problema 26.

Além disso, ao usar no modelo as variáveis individuais, torna-se possível identificar áreas onde existe um risco maior para os bebês, controlando pelos fatores de risco individuais. $\mathrm{Ou}$ seja, as áreas onde morrem mais crianças, mesmo controlando pelo peso ao nascer, idade gestacional e demais fatores conhecidos de risco.

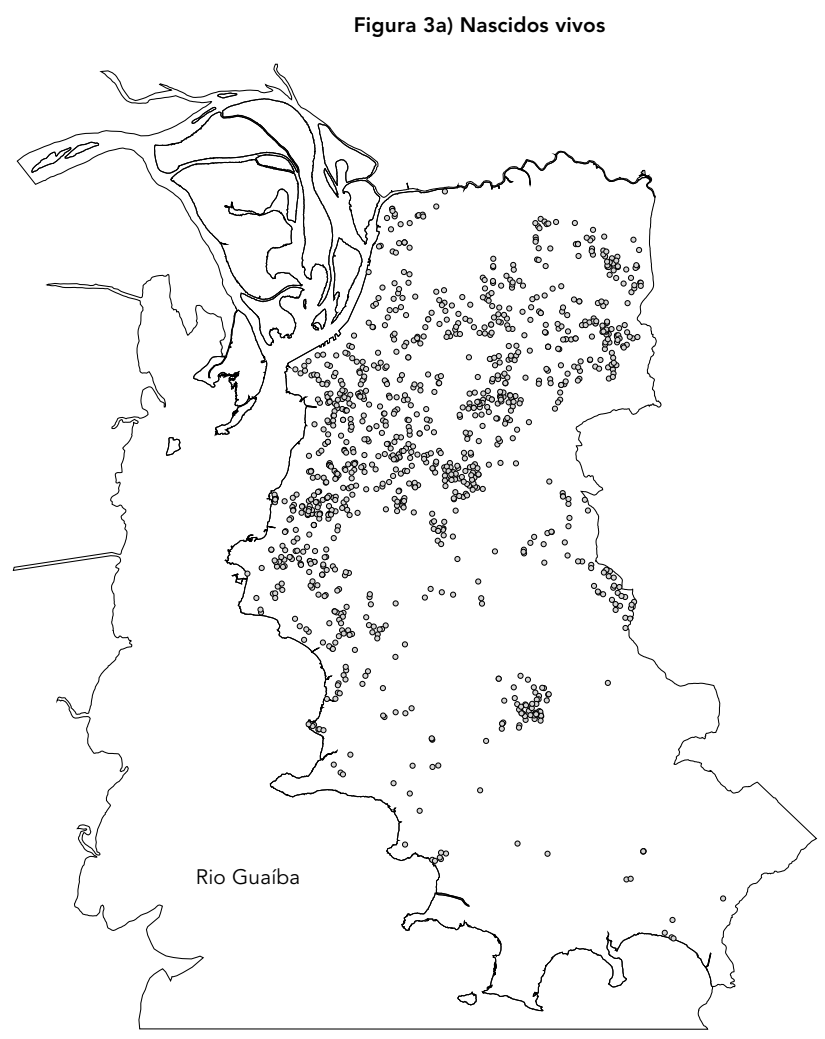

- nascidos vivos (amostra)

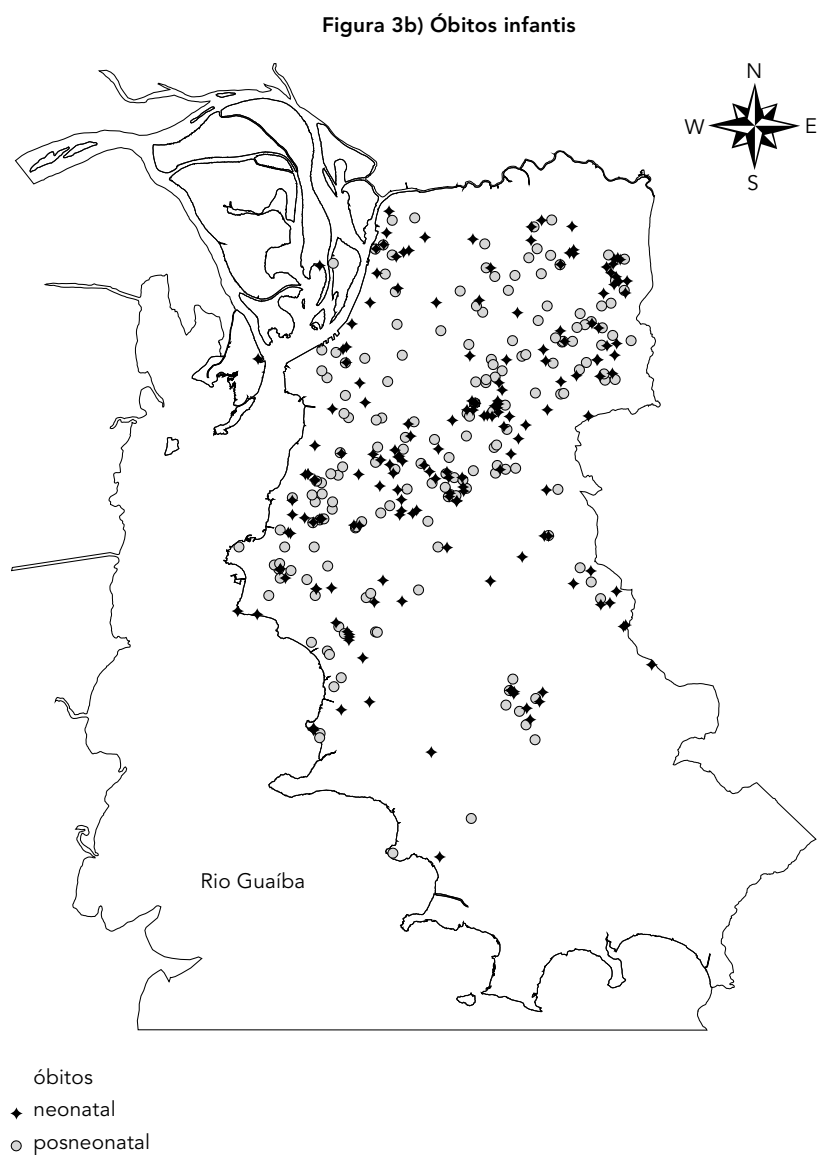




\section{Figura 3 (continuação)}

Localização dos óbitos infantis, de amostra de nascidos vivos e mapa de risco Porto Alegre, Rio Grande do Sul, Brasil, 1998.

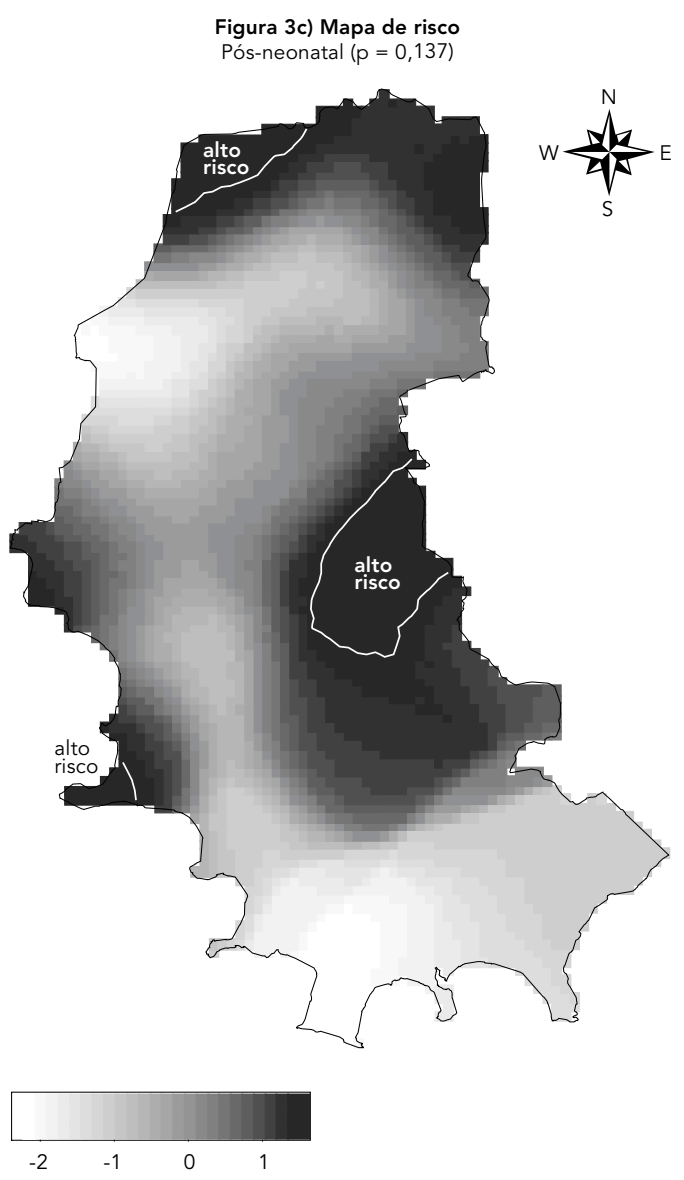

Fonte: Shimakura et al. 24.
Com este modelo é possível orientar a atuação do serviço de saúde, inclusive na busca de outros fatores de risco ou proteção não disponíveis nos sistemas de informações de rotina. Estes podem estar no campo da assistência à saúde, por exemplo na demora à assistência ao parto ou falta de pré-natal adequado. Podem ainda estar relacionados a condições ambientais, falta de saneamento e poluição atmosférica, desencadeando alergias respiratórias e agravando outras condições mórbidas. Mesmo fatores individuais, quando concentrados em áreas específicas, por exemplo, de imigrantes recémchegados, podem ser localizados desta forma, desencadeando novas investigações, com ou sem o uso de SIG.

Os passos da modelagem incluem o relacionamento dos bancos de mortalidade e nascidos vivos (linkage); o georreferenciamento; o ajuste do modelo e a visualização dos resultados. O linkage é um problema geral no uso dos sistemas de informações em saúde. Na grande maioria dos municípios do país é grande a dificuldade de relacionar os dois bancos - nascimentos e óbitos - mesmo com auxílio de programa especializado como RecLink 27 . No caso deste estudo foi utilizado o código atribuído pelo Centro de Informações para a Saúde (CEDIS) de Porto Alegre. Da mesma forma, o georreferenciamento de nascimentos e óbitos foi feito utilizando o SIG implantado na prefeitura - menos de 5,0\% dos registros não foram localizados, média muito inferior à grande maioria dos locais, mesmo onde existem sistemas de cadastramento de logradouros. Nesta etapa é importante incluir considerações éticas sobre o uso da coordenada precisa, que permite a identificação da residência do cidadão. O ideal seria um sistema automatizado que incluísse um "ruído" aleatório nas coordenadas, que sem impossibilitar o tratamento estatístico impedisse o uso por pessoas desautorizadas das informações médicas relativas aos cidadãos.

O modelo estatístico pode ser ajustado no $\mathrm{R}$, apesar da biblioteca (SPATGAM) ainda estar em desenvolvimento. A regressão logística semiparamétrica na estimação da razão de densidades gera uma superfície de risco e permite a construção dos contornos de tolerância, identificando onde o risco é significativamente diferente da média da região, estimativa esta obtida por simulação 25 .

A etapa final, de visualização do "mapa" de risco, idealmente deve ser feita no SIG, importando a matriz resultante do kernel com a superfície de risco e as linhas identificando as áreas significativamente diferentes da média global (alto e baixo risco) como uma imagem 
raster. Desta forma seria possível acrescentar outras camadas de informação, tais como a localização dos postos e hospitais, permitindo analisar à distância as áreas de sobre-risco ou informações das condições de saneamento. A simples identificação de bairros e respectivos responsáveis locais, bem como a discussão com as comissões de gestores já seria facilitada. Novamente a falta de integração entre programa estatístico e SIG é limitante.

\section{Uso de serviços de saúde}

As aplicações de métodos de análise espacial em estudos sobre a utilização de serviços de saúde são as mais variadas. As técnicas específicas de análise de redes, aplicadas, por exemplo, na otimização de rotas de ambulâncias, não serão discutidas aqui. O que abordaremos é o acesso da clientela, avaliando com isso os condicionantes geográficos e sócio-econômicos, e a própria qualidade do serviço prestado. A investigação das desigualdades regionais na acessibilidade aos serviços de saúde tem como um dos objetivos a definição das unidades de observação, caracterizadas por incluírem, dentro de seus limites geográficos, a maior parte dos deslocamentos em busca de atendimento. Os trabalhos que discutiremos baseiam-se na análise de padrões de origem-destino de pacientes, visando a identificar e medir propriedades que emergem da conexão entre unidades e, assim, compreender as características dos fluxos, classificando segundo hierarquia, volume, direção e sentido.

Além disso, destas trajetórias surgem regiões que compartilham serviços - regiões de abrangência ou mercados. Regiões podem ser caracterizadas em termos formais, com ênfase na homogeneidade de algum elemento do território, ou funcionais, com ênfase nos sistemas de relações funcionais que caracterizam um sistema territorial integrado. Regiões homogêneas são definidas com base em elementos característicos presentes. Neste tipo de região, é reduzida a variação na densidade ou na intensidade de ocorrência dos elementos definidores no âmbito de cada região. Regiões funcionais, por outro lado, são delimitadas com base no movimento e podem exibir grande variação na intensidade dos fluxos no seu interior. As relações funcionais entre os consumidores em uma área e os fornecedores de bens e serviços no centro, e as trajetórias no espaço geográfico envolvidas na obtenção e fornecimento desses bens e serviços são as principais características das regiões funcionais 28 . A divisão em dois ti- pos polares deve ser considerada à luz das observações de Milton Santos 29 (p. 25), de que “os arranjos espaciais não se dão apenas através de figuras formadas de pontos contínuos $e$ contíguos. Hoje, ao lado das manchas, ou por sobre essas manchas, há também, constelações de pontos descontínuos, mas interligados, que definem um espaço de fluxos reguladores".

Analisar as regiões segundo o uso, ou acesso, dos serviços de saúde permite comparar as diferentes estratégias de obtenção de assistência, conforme a complexidade do procedimento e as alternativas existentes, bem como a área de cobertura dos serviços e a responsabilidade destes sobre a qualidade do serviço prestado.

\section{Áreas de cobertura}

As áreas de cobertura de unidades de saúde, quando são definidas baseando-se na origem geográfica dos usuários, podem ser denominadas como "mercados" destas unidades. Estes mercados constituem-se a partir de aspectos de acesso viário e histórico. A Figura 4a mostra alguns aspectos da malha viária - principais rotas de transportes coletivos - do Município de Olinda, bem como a localização dos centros de saúde responsáveis pelo atendimento à hanseníase 30 . Duas unidades de saúde são localizadas fora dos limites do Município, o que dada a grande densidade demográfica e perfeita continuidade em toda a região metropolitana do Recife não é impeditivo para o deslocamento da população.

A Figura 4 (b e c) mostra, em dois períodos (1991-1995 e 1996-2000), os mercados dessas unidades, considerando apenas os dominantes, ou seja, as áreas onde mais de 50,0\% do atendimento é feito por uma determinada unidade. Pode-se observar a mudança ocorrida na década, com a maior participação das unidades locais (Peixinhos e São Benedito) em períodos mais recentes. A importância deste tipo de análise é grande, permitindo qualificar o atendimento realizado pelos serviços, avaliar os resultados dos investimentos em treinamento, expansão de rede com o programa de saúde da família, entre outros.

Os procedimentos para esta análise são relativamente simples, mas, novamente, muito trabalhosos pela falta de integração entre SIG e pacote estatístico. Como Olinda não dispõe de SIG com informações de arruamento, o georreferenciamento somente foi possível para setor censitário, utilizando na modelagem as coordenadas do centróide.

Tendo exportado os dados georreferenciados para o R, estima-se a superfície da densi- 


\section{Figura 4}

(a) Principais corredores da rede viária e localização dos postos e centros de saúde que atendem à hanseníase; (b) e (c) evolução de áreas de domínio de atendimento segundo unidades de saúde. Olinda, Pernambuco, Brasil, em dois períodos: 1991/1995 e 1996/2000.

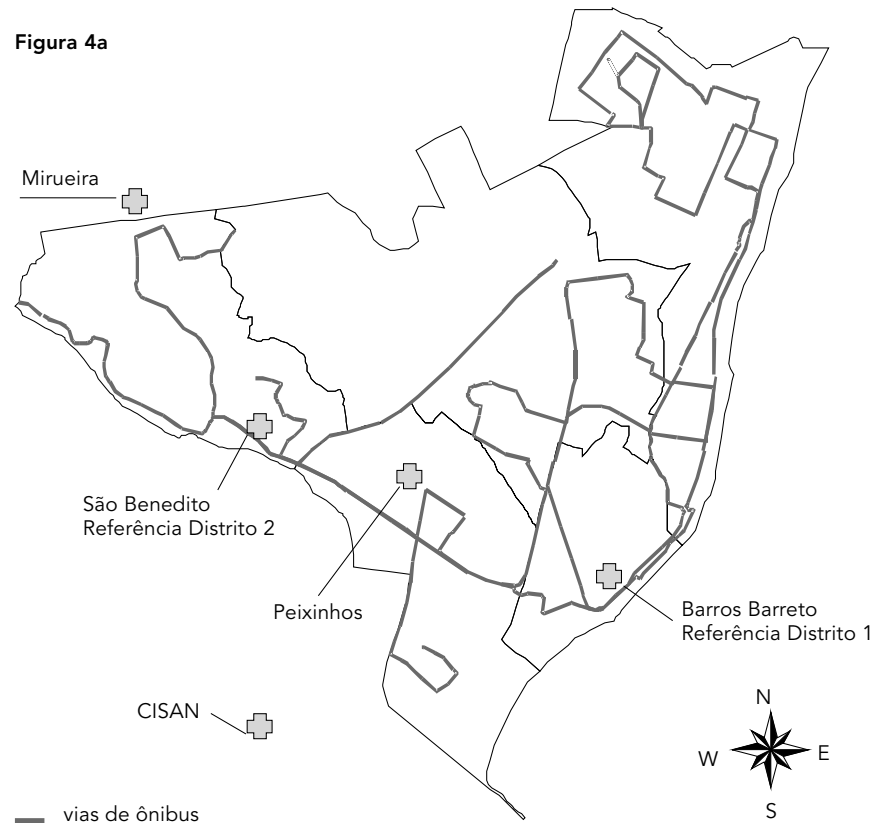

_ limites municipais e de distritos

(continua) tatístico e SIG. Além disso, a vetorização não é trivial no programa utilizado.

\section{Redes}

O estudo de redes baseia-se no conceito de fluxo de pacientes entre áreas, municípios, bairros ou regiões. Cada unidade de área é um nó da rede, que recebe e/ou envia pacientes para outros nós. Todas as unidades geográficas de análise, neste caso os municípios, são ordenadas utilizando algum indicador pertinente, por exemplo, oferta de leitos, gasto total em saúde, ou procedimentos oferecidos segundo complexidade. Em função de hierarquia estabelecida os fluxos de pacientes são classificados em: hierárquico ascendente, contra-hierárquico descendente e transversal 31.

No exemplo em estudo, analisou-se o fluxo do município de residência dos pacientes internados pelo SUS (Sistema Único de Saúde) e o município onde se localiza o hospital. A hierarquia entre os municípios foi definida pelo custo total das internações realizadas no município, sendo considerados ascendentes os fluxos entre municípios quando os pacientes se deslocam na direção do município que tem maior gasto total. Utilizou-se os 39 procedimentos médicos mais freqüentes e responsáveis por $61,3 \%$ do total das internações custeadas pelo SUS no ano 200028

A Figura 5 apresenta a rede entre municípios de níveis 1,2 e 3 , determinada pelo fluxo de atendimentos. Nas internações básicas no Brasil existem apenas dois centros de nível 1 (o topo da rede): São Paulo e Porto Alegre. A rede comandada por Porto Alegre é restrita à área do Rio Grande do Sul, e todos os outros estados estão ligados, direta ou indiretamente, a São Paulo. A mais extensa das redes de nível 2 é a de Goiânia que conta com 130 centros de nível 3, dos quais $70,0 \%$ não estabelecem ramificação própria, e nela estão as capitais estaduais abaixo do nível 3 .

A fonte dos dados foi o sistema de informações hospitalares SIH-SUS. A construção da matriz origem-destino foi feita em SAS ${ }^{\circledR}$, dado o número de municípios (mais de 5 mil), mas em estudos mais localizados pode ser feita no TabWin, programa desenvolvido pelo DATASUS, cuja nova versão incorpora algoritmos de visualização de fluxos origem-destino (http: //www.datasus.gov.br/tabwin/apresent.htm, acessado em 26/Dez/2004). Para a classificação dos fluxos e identificação foi utilizado programa também gratuito, disponível na Internet 31 . Para cada município, identifica-se aquele hierarquicamente superior que interna a maioria dos pacientes, o superior imediato é identifica- 
do, e este arquivo, devolvido ao SIG, permite desenhar as ligações entre municípios. O problema maior mais uma vez está nas passagens entre programas e na falta de procedimentos que automatizem as transferências, e a possível introdução de erros entre as etapas.

\section{Comentários finais}

Os problemas aqui discutidos permitem estimar a importância da aplicação de técnicas de análise espacial no campo da saúde coletiva, identificar as principais áreas de estrangulamento na disseminação da tecnologia, além de apresentar a contribuição de pesquisadores brasileiros no cenário internacional. Evidentemente, algumas técnicas seriam dificilmente aplicáveis por secretarias de saúde na sua rotina, outras, entretanto, não apresentam dificuldade teórica maior. E ao menos poderiam ser usadas pelas agências reguladoras, por exemplo, a Agência Nacional de Vigilância Sanitária, pela Secretaria de Vigilância em Saúde ou em algumas secretarias estaduais e municipais de saúde melhor aparelhadas. O problema maior não está na técnica em senso estrito, mas nas dificuldades de construção dos indicadores, matrizes de vizinhança e interface entre pacotes estatísticos e SIG. E, ainda mais importante, no ainda pequeno domínio das técnicas necessárias e na troca limitada entre os diversos profissionais que podem contribuir para a construção deste conhecimento. Vale chamar a atenção para recentes iniciativas que permitem integrar os programas TabWin e $\mathrm{R}$, que amplia imensamente a capacidade de análise de dados do TabWin, e o lançamento, em dezembro de 2004, de versão do TerraView (http:// www.dpi.inpe.br/terraview/index.php, acessado em 28/Dez/2004), um SIG com recursos de consulta e análise de dados espaciais, incluindo mapas bayesianos.

Neste trabalho não abordamos diversos outros problemas onde métodos de análise espacial são imprescindíveis. Detecção de cluster espaço-temporais e modelagem ambiental são áreas de grande desenvolvimento, cabendolhes um espaço exclusivo. O uso de imagens de satélite tem enorme potencial para a saúde na estimação de áreas de expansão urbana desordenada e identificação de suscetibilidade à ocupação vetorial 32. Entretanto, o diagnóstico nestas abordagens é provavelmente semelhante: mesmo que as técnicas já estejam bem resolvidas do ponto de vista da modelagem, sua implementação no dia-a-dia dos pesquisadores da área da saúde é pouco amistosa.

\section{Figura 4 (continuação)}

(a) Principais corredores da rede viária e localização dos postos e centros de saúde que atendem à hanseníase; (b) e (c) evolução de áreas de domínio de atendimento segundo unidades de saúde. Olinda, Pernambuco, Brasil, em dois períodos: $1991 / 1995$ e 1996/2000.
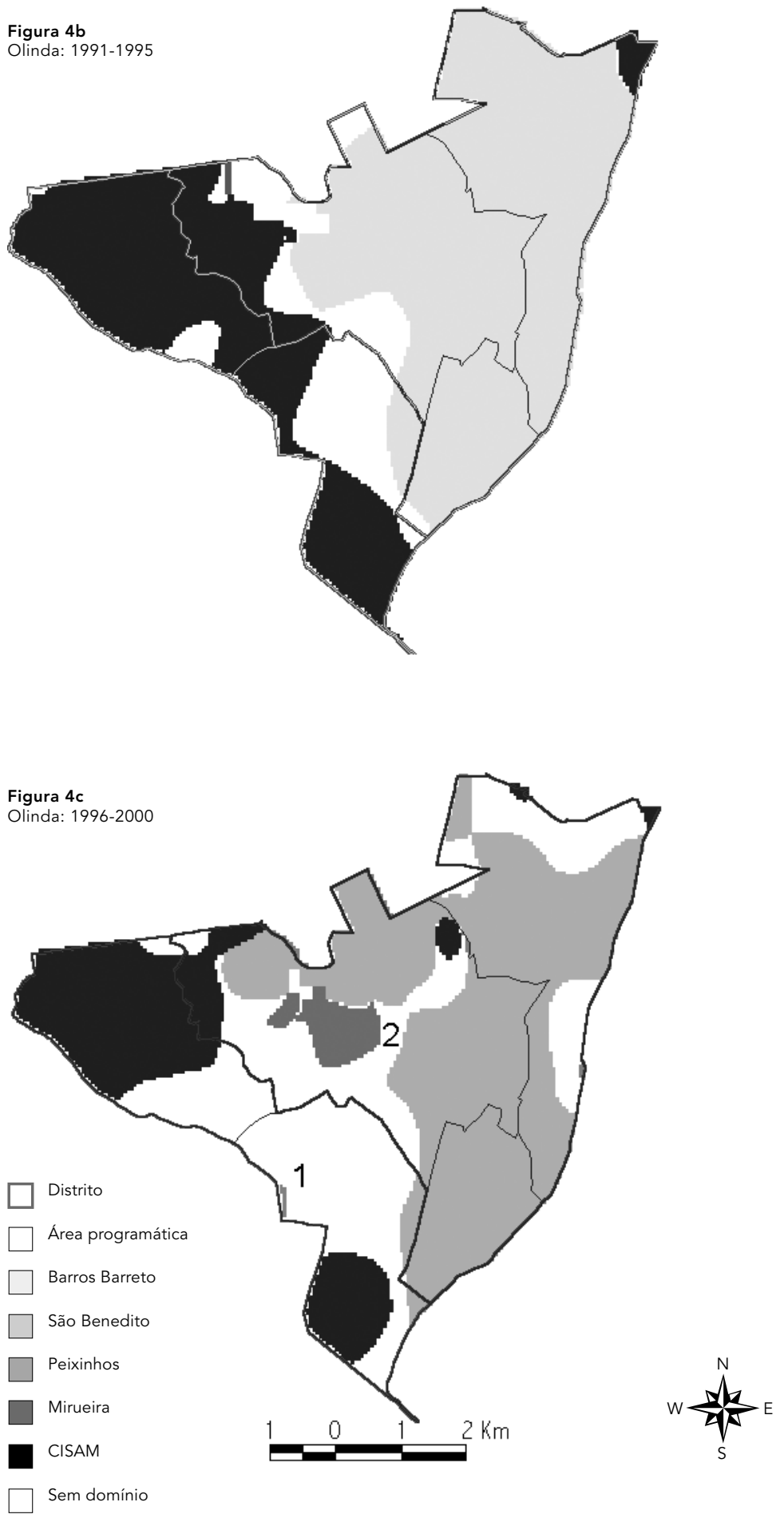

Fonte: Lapa 30 


\section{Figura 5}

Rede assistencial entre município de residência e município de internação. Brasil, 2000.

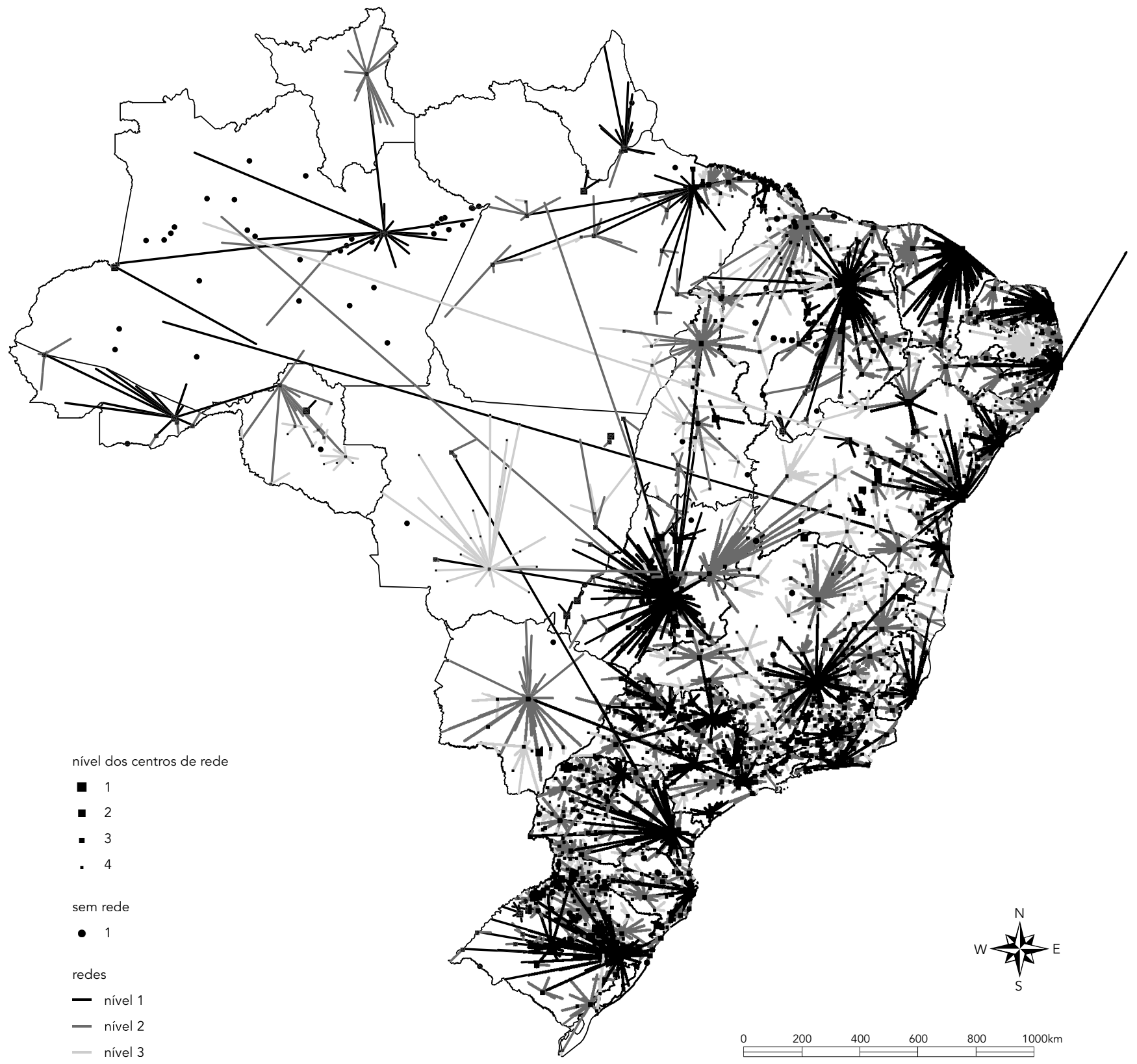

Fonte: Oliveira et al. 28 
O ponto principal deste trabalho foi apresentar aplicações substantivas na saúde pública, visando a estimular a discussão sobre implementação de interfaces e "diálogo" verdadeiramente amistoso entre programas e com o usuário. Além disso, cabe lembrar que a finalidade social última dos trabalhos na saúde coletiva deve ser um estímulo, sempre que possí- vel, ao desenvolvimento de software livre, onde parta da própria comunidade de usuários as idéias e demandas que dão rumo aos programas. Esperamos que a discussão destes temas contribua na construção desta proposta: melhor tecnologia, mais democracia na disseminação da informação, mais saúde.

\section{Resumo}

Estudos mostram que a localização espacial dos eventos em saúde e os Sistemas de Informações Geográficas (SIG), têm papel destacado e vêm se tornando mais freqüentes na literatura da área de saúde pública. Entretanto, os métodos e software necessários ao aprofundamento desta abordagem ainda apresentam limitações devido à dificuldade de uso e desconhecimento dos pesquisadores e profissionais da área. $\mathrm{O} o b-$ jetivo deste trabalho é apresentar algumas aplicações exemplares de métodos voltados para a análise de padrões espaciais de eventos em saúde, discutindo vantagens, desvantagens e aplicabilidade dos modelos propostos, particularmente no campo dos estudos ecológicos e na análise do uso de serviços de saúde, além de sistematizar o estado da arte da utilização de metodologias de análise espacial na saúde pública.

Análise Espacial; Sistemas de Informação Geográfica; Literatura de Revisão

\section{Colaboradores}

M. S. Carvalho efetuou a análise e discussão dos estudos utilizados como exemplos. R. Souza-Santos efetuou a revisão sistemática e tabulação dos dados. A discussão, redação e estruturação do texto foi desenvolvida por ambos os autores.

\section{Agradecimentos}

Aos autores dos trabalhos utilizados como exemplo e aos periódicos que gentilmente cederam as figuras. 


\section{Referências}

1. Gallacher J. Values and science. J Clin Epidemiol 2001; 54:1275-7.

2. Morgenstern, H. Ecologic studies. Modern epidemiology. Boston: Lippincott Williams \& Wilkins Publishers; 1998.

3. Rose G. Sick individuals and sick populations with discussion. Int J Epidemiol 2001; 30:427-32.

4. Susser M. The logic in ecological: I. the logic of analysis. Am J Public Health 1994; 84:825-9.

5. Diez-Roux AV. Bringing context back into epidemiology: variables and fallacies in multilevel analysis. Am J Public Health 1998; 88:216-22.

6. Pickett KE, Pearl M. Multilevel analyses of neighbourhood socioeconomic context and health outcomes: a critical review. J Epidemiol Community Health 2001; 55:111-22.

7. Bailey T. Spatial statistics methods in health. Cad Saúde Pública 2001; 17:1083-98.

8. Elliott P, Wartenberg D. Spatial epidemiology: current approaches and future challenges. Environ Health Perspect 2004; 112:998-1006.

9. Rushton G. Public health, GIS, and spatial analytic tools. Annu Rev Public Health 2003; 24:43-56.

10. Elliott P, Wakefield J, Best N, Briggs D. Spatial epidemiology: methods and applications. London: Oxford University Press; 2001.

11. Assunção RM. Estatística espacial com aplicações em epidemiologia, economia, sociologia. São Carlos: ABE; 2001.

12. Lawson A. Statistical methods in spatial epidemiology. Sussex: John Wiley \& Sons; 2001.

13. Cromley E, McLafferty S, Cromley EK, McLafferty SL. GIS and public health. New York: Guilford Press; 2002.

14. Monteiro AMV. Projeto SAUDAVEL - Sistema de Apoio Unificado para Detecção e Acompanhamento em Vigilância EpidemioLógica. http://saudavel. dpi.inpe.br/ (acessado em 14/Ago/2003).

15. Cressie N. Statistics for spatial data. New York: Wiley; 1991.

16. Souza WV, Barcellos CC, Brito AM, Carvalho MS, Cruz OG, Albuquerque MF, et al. Aplicação de modelo bayesiano empírico na análise espacial da ocorrência de hanseníase. Rev Saúde Pública 2001; 35:474-80.

17. Clayton D, Kaldor J. Empirical Bayes estimates of age-standardized relative risks for use in disease mapping. Biometrics 1987; 43:671-81.

18. Bivand R. Spatial econometrics functions in R: classes and methods. Journal of Geographical Systems 2002; 4:405-21.

19. Ihaka R, Gentleman R. R: a language for data analysis and graphics. Journal of Computational and Graphical Statistics 1996; 5:299-314.

20. Bailey TC, Brewer M, Carvalho MS, Lapa TM, Souza WV. Bayesian modelling of under-reporting in disease surveillance. Ann Epidemiol; no prelo.

21. Spiegelhalter DJ, Thomas A, Best NG. WinBUGS. Cambridge: MRC Biostatistics Unit; 1999.

22. Bailey T, Gatrel A. Interactive spatial data analysis. London: Longman; 1995.

23. Hastie TJ, Tibishirani RJ. Generalized additive models. London: Chapman and Hall; 1990.

24. Shimakura SE, Carvalho MS, Aerts DRGC, Flores
R. Distribuição espacial do risco: modelagem da mortalidade infantil em Porto Alegre, Rio Grande do Sul, Brasil. Cad Saúde Pública 2001; 17:1251-61.

25. Kelsall JE, Diggle PJ. Spatial variation in risk of disease: a nonparametric binary regression approach. Appl Stat 1998; 47:559-73.

26. Fotheringham AS, Brunsdon C, Charlton M. Quantitative geography: perspectives on spatial analysis. London: Sage Publications; 2000.

27. Camargo Jr. KR, Coeli CM. Reclink: aplicativo para o relacionamento de bases de dados, implementando o método "probabilistic record linkage". Cad Saúde Pública 2000; 16:439-47.

28. Oliveira EXG, Travassos C, Carvalho MS. Territórios do Sistema Único de Saúde: mapeamento das redes de atenção hospitalar. Cad Saúde Pública 2004; 20:386-402.

29. Santos M. A natureza do espaço: técnica e tempo. Razão e emoção. 3a Ed. São Paulo: Editora Hucitec; 1996.

30. Lapa TM. Análise da demanda de casos de hanseníase aos serviços de saúde através do uso de técnicas de análise espacial [Tese de Doutorado]. Recife: Centro de Pesquisa Aggeu Magalhães, Fundação Oswaldo Cruz; 2003.

31. Rabino GA, Occelli S. Understanding spatial structure from network data: theoretical considerations and applications. CYBERGEO 1997; 29.

32. Correia VRM, Carvalho MS, Sabroza PC, Vasconcelos $\mathrm{CH}$. Remote sensing as a tool to survey endemic diseases in Brazil. Cad Saúde Pública 2004; 20:891-904.

33. Joines JD, Hertz-Picciotto I, Carey TS, Gesler W, Suchindran C. A spatial analysis of county-level variation in hospitalization rates for low back problems in North Carolina. Soc Sci Med 2003; 56:2541-53.

34. Franco-Marina F, Villalba-Caloca J, Segovia N, Tavera L. Spatial indoor radon distribution in Mexico City. Sci Total Environ 2003; 317:91-103.

35. Gorman DM, Speer PW, Gruenewald PJ, Labouvie EW. Spatial dynamics of alcohol availability, neighborhood structure and violent crime. J Stud Alcohol 2001; 62:628-36.

36. Hijar M, Trostle J, Bronfman M. Pedestrian injuries in Mexico: a multi-method approach. Soc Sci Med 2003; 57:2149-59.

37. Jerrett M, Burnett RT, Willis A, Krewski D, Goldberg MS, DeLuca P, et al. Spatial analysis of the air pollution-mortality relationship in the context o ecologic confounders. J Toxicol Environ Health 2003; 66:1735-77.

38. Miranda ML, Dolinoy DC, Overstreet MA. Mapping for prevention: GIS models for directing childhood lead poisonin revention programs. Environ Health Perspect 2002; 110:947-53.

39. O'Brien DJ, Kaneene JB, Getis A, Lloyd JW, Swanson GM, Leader RW. Spatial and temporal comparison of selected cancers in dogs and humans, Michigan, USA, 1964-1994. Prev Vet Med 2000; 47:187-204.

40. Selvin S, Merrill DW. Adult leukemia: a spatial analysis. Epidemiology 2002; 13:151-6.

41. Williams PL. Exploring spatio-temporal patterns of mortality using mixed effects models. Stat Med 
2000; 19:2251-63.

42. Forand SP, Talbot TO, Druschel C, Cross PK. Data quality and the spatial analysis of disease rates: congenital malformation in New York State. Health Place 2002; 8:191-9.

43. Bunnell JE, Price SD, Das A, Shields TM, Glass GE. Geographic information systems and spatial analysis of adult Ixodes scapulari (Acari: Ixodidae) in the Middle Atlantic region of the U.S.A. J Med Entomol 2003; 40:570-6.

44. Chaput EK, Meek JI, Heimer R. Spatial analysis of human granulocytic ehrlichiosis near Lyme, Connecticut. Emerg Infect Dis 2002; 8:943-8.

45. Glavanakov S, White DJ, Caraco T, Lapenis A, Robinson GR, Szymanski BK, et al. Lyme disease in New York State: spatial pattern at a regional scale. Am J Trop Med Hyg 2001; 65:538-45.

46. Greig JD, Michel P, Wilson JB, Lammerding AM, Majowicz SE, Stratton J, et al. A descriptive analysis of giardiasis cases reported in Ontario, 19901998. Can J Public Health 2001; 92:361-5.

47. Kinman EL. Evaluating health service equity at a primary care clinic in Chilimarca Bolivia. Soc Sci Med 1999; 49:663-78.

48. Gall M. Where to go? Strategic modelling of access to emergency shelters in Mozambique. Disasters 2004; 28:82-97.

49. Gemperli A, Vounatsou P, Kleinschmidt I, Bagayoko M, Lengeler C, Smith T. Spatial patterns of infant mortality in Mali: the effect of malaria endemicity. Am J Epidemiol 2004; 159:64-72.

50. Gyapong JO, Kyelem D, Kleinschmidt I, Agbo K, Ahouandogbo F, Gaba J, et al. The use of spatial analysis in mapping the distribution of bancroftian filariasis in four West African countries. Ann Trop Med Parasitol 2002; 96:695-705.

51. Gyapong JO, Remme JH. The use of grid sampling methodology for rapid assessment of the distribution o bancroftian filariasis. Trans R Soc Trop Med Hyg 2001; 95:681-6.

52. Jeanne I. Malaria and schistosomiasis: 2 examples using systems of geographical information and teledetection in Madagascar. Bull Soc Pathol Exot 2000; 93:208-14.

53. Kleinschmidt I, Sharp BL, Mueller I, Vounatsou P. Rise in malaria incidence rates in South Africa: a small-area spatial analysis of variation in time trends. Am J Epidemiol 2002; 155:25764.

54. Kleinschmidt I, Sharp BL, Clarke GP, Curtis B, Fraser C. Use of generalized linear mixed models in the spatial analysis of small-are malaria incidence rates in Kwazulu Natal, South Africa. Am J Epidemiol 2001; 153:1213-21.

55. Henrich TJ, Hutchaleelaha S, Jiwariyavej V, Barbazan P, Nitatpattana N, Yoksa S, et al. Geographic dynamics of viral encephalitis in Thailand. Microbes Infect 2003; 5:603-11.

56. Pinheiro RS, Travassos C, Gamerman D, Carvalho MS. Mercados hospitalares em área urbana: uma abordagem metodológica. Cad Saúde Pública 2001; 17:1111-21.

57. Beato Filho CC, Assunção RM, Silva BF, Marinho FC, Reis IA, Almeida MC. Conglomerados de ho- micídios e o tráfico de drogas em Belo Horizonte, Minas Gerais de 1995 a 1999. Cad Saúde Pública 2001; 17:1163-71.

58. Freitas ED, Paim JS, Silva LMV, Costa, MCN. Evolução e distribuição espacial da mortalidade por causas externas em Salvador, Bahia, Brasil. Cad Saúde Pública 2000; 16:1059-70.

59. Santos SM, Barcellos C, Carvalho MS, Flores R. Detecção de aglomerados espaciais de óbitos por causas violentas em Porto Alegre, Rio Grande do Sul, Brasil, 1996. Cad Saúde Pública 2001; 17:114151.

60. Andrade CL, Szwarcwald CL. Análise espacial da mortalidade neonatal precoce no Município do Rio de Janeiro, 1995-1996. Cad Saúde Pública 2001; 17:1199-210.

61. Costa MCN, Azi PA, Paim JS, Silva LMV. Mortalidade infantil e condições de vida: a reprodução das desigualdades sociais em saúde na década de 90. Cad Saúde Pública 2001; 17:555-67.

62. Malta DC, Almeida MCM, Dias MAS, Merhy EE. A mortalidade infantil em Belo Horizonte, Minas Gerais, Brasil, por área de abrangência dos Centros de Saúde (1994-1996). Cad Saúde Pública 2001; 17:1189-98.

63. Morais Neto OL, Barros MB, Martelli CM, Silva SA, Cavenaghi SM, Siqueira Jr. JB. Diferenças no padrão de ocorrência da mortalidade neonatal e pós-neonatal no Município de Goiânia, Brasil, 1992-1996: análise espacial para identificação das áreas de risco. Cad Saúde Pública 2001; 17:124150.

64. Braga C, Ximenes RAA, Albuquerque MFPM, Souza WV, Miranda J, Brayner F, et al. Avaliação de indicador sócio-ambiental utilizado no rastreamento de áreas de transmissão de filariose linfática em espaços urbanos. Cad Saúde Pública 2001; 17:1211-8.

65. Dias PRTP, Nobre FF. Análise dos padrões de difusão espacial dos casos de AIDS por estados brasileiros. Cad Saúde Pública 2001; 17:1173-87.

66. Barcellos C, Sabroza PC. Socio-environmental determinants of the leptospirosis outbreak of 1996 in western Rio de Janeiro: a geographical approach. Int J Environ Health Res 2000; 10:301-13.

67. Camargo-Neves VL, Katz G, Rodas LA, Poletto DW, Lage LC, Spinola RM, et al. Utilização de ferramentas de análise espacial na vigilância epidemiológica de leishmaniose visceral americana, Araçatuba, São Paulo, Brazil, 1998-1999. Cad Saúde Pública 2001; 17:1263-7.

68. Lapa TM, Ximenes R, Silva NN, Souza W, Albuquerque M, Campozana G. Vigilância da hanseníase em Olinda, Brasil, utilizando técnicas de análise espacial. Cad Saúde Pública 2001; 17:115362.

69. Oliveira CD, Assunção RM, Reis IA, Proietti FA. Spatial distribution of human and canine visceral leishmaniasis in Belo Horizonte, Minas Gerais State, Brasil, 1994-1997. Cad Saúde Pública 2001; 17:1231-9.

70. Szwarcwald CL, Bastos FI, Barcellos C, Esteves MA, Castilho EA. Dinâmica da epidemia de AIDS no Município do Rio de Janeiro, no período de 
1988-1996: uma aplicação de análise estatística espaço-temporal. Cad Saúde Pública 2001; 17: 1123-40.

71. Szwarcwald CL, Bastos FI, Esteves MA, Andrade CL. A disseminação da epidemia da AIDS no Brasil, no período de 1987-1996: uma análise espacial. Cad Saúde Pública 2000; 16 Suppl 1:7-19.

72. Tomazelli J, Czeresnia D, Barcellos C. Distribuição dos casos de AIDS em mulheres no Rio de Janeiro, de 1982 a 1997: uma análise espacial. Cad Saúde Pública 2003; 19:1049-61.

73. Andrade ALSS, Silva SA, Martelli CMT, Oliveira RM, Morais Neto OL, Siqueira Jr. JB, et al. Population-based surveillance of pediatric pneumonia: use of spatial analysis in an urban area of Central Brazil. Cad Saúde Pública 2004; 20:411-21.

74. Kawa H, Sabroza PC. Espacialização da leishmaniose tegumentar na cidade do Rio de Janeiro. Cad Saúde Pública 2002; 18:853-65.

75. Monteiro-de-Castro MS, Assunção RM, Proietti FA. Spatial distribution of the Human T-Lymphotropic Virus types I and II (HTLV-I/II) infection among blood donors of Hemominas Foundation, Belo Horizonte, Minas Gerais State, Brazil, 1994-1996; Cad Saúde Pública 2001; 17:1219-30.

76. Souza-Santos R, Carvalho MS. Análise da distribuição espacial de larvas de Aedes aegypti na Ilha do Governador, Rio de Janeiro, Brasil. Cad Saúde Pública 2000; 16:31-42.

77. Werneck GL, Maguire JH. Spatial modeling using mixed models: an ecologic study of visceral leishmaniasis in Teresina, Piauí State, Brazil. Cad Saúde Pública 2002; 18:633-7.

78. Werneck GL, Costa CH, Walker AM, David JR, Wand M, Maguire JH. The urban spread of visceral leishmaniasis: clues from spatial analysis. Epidemiology 2002; 13:364-7.

79. Barcellos C, Sabroza PC. The place behind the case: leptospirosis risks and associated environmental conditions in a flood-related outbreak in Rio de Janeiro. Cad Saúde Pública 2001; 17 Suppl: 59-67.
80. Antunes JL, Frazão P, Narvai PC, Bispo CM, Pegoretti T. Spatial analysis to identify differentials in dental needs by area-base measures. Community Dent Oral Epidemiol 2002; 30:133-42.

81. Santos SM, Noronha CP. Padrões espaciais de mortalidade e diferenciais socioeconômicos na cidade do Rio de Janeiro. Cad Saúde Pública 2001; 17:1099-110.

82. Jarup L, Best N, Toledano MB, Wakefield J, Elliott P. Geographical epidemiology of prostate cancer in Great Britain. Int J Cancer 2002; 97:695-9.

83. Knorr-Held L, Ralsser G, Becker N. Disease mapping of stage-specific cancer incidence data. Biometrics 2002; 58:492-501.

84. Pugliatti M, Solinas G, Sotgiu S, Castiglia P, Rosati G. Multiple sclerosis distribution in northern Sardinia: spatial cluster analysis of prevalence. Neurology 2002; 58:277-82.

85. Strauss R, Pfeifer C, Ulmer H, Muhlberger V, Pfeiffer KP. Spatial analysis of Percutaneous Transluminal Coronary Angioplasty (PTCA) in Austria. Eur J Epidemiol 1999; 15:451-9.

86. Tukiendorf A. An ecological analysis of leukemia incidence around the highest 137Cs concentration in Poland. Cancer Causes Control 2001; 12: 653-9.

87. Thomas CJ, Lindsay SW. Local-scale variation in malaria infection amongst rural Gambian children estimated by satellite remote sensing. Trans R Soc Trop Med Hyg 2000; 94:159-63.

88. Hyndman JC, Holman CD, de Klerk NH. A comparison of measures of access to child health clinics and the implication or modelling the location of new clinics. Aust N Z J Public Health 1999; 23:189-95.

Recebido em 13/Out/2004

Versão final reapresentada em 03/Jan/2005 Aprovado em 04/Jan/2005 